\title{
A FORMAÇÃO DO PROFESSOR DE MATEMÁTICA E O TRABALHO COM PROJETOS NA ESCOLA
}

\section{Mathematics teacher education and project work in school}

\author{
Maria Dirlene da Silva Cattai ${ }^{1}$ \\ Miriam Godoy Penteado ${ }^{2}$
}

Resumo: O objetivo do presente texto é apresentar os resultados de uma pesquisa que procurou discutir a formação dos professores de Matemática que trabalham com projetos e documentar a maneira da implementação dessa proposta na escola. Os dados são provenientes de entrevistas com dez professores de Matemática, os quais atuam no Ensino Fundamental ou Médio. Seus relatos possibilitam identificar três formas diferentes de trabalhos com projetos: i) individualmente e por iniciativa própria; ii) por sugestão da escola, de forma fragmentada; iii) coletivamente. Não há indícios de que a formação inicial desses professores os tenha influenciado a trabalhar com projetos. Esse preparo foi construído ao longo de suas carreiras, através da participação em cursos de formação continuada, da experiência com a prática e das interferências de suas características pessoais.

Palavras-chave: Trabalho com projetos. Formação de professores de matemática. Trabalho docente. Educação matemática.

\begin{abstract}
This paper presents the results of research aiming at discussing the relationship between mathematics teacher education and the development of project work in teaching practice. The data are taken from interviews with ten secondary and high school mathematics teachers as well as two questionnaires answered by each of them. It was possible to identify three different forms of working with projects: i) individually- teachers' own initiative; ii) by school recommendation- in a fragmented manner; iii) collectively. There are no evidences that the pre-service education influenced their work with projects. This preference was developed during their careers through participation on in-service courses, practical experience, and personal characteristics. In-service teacher education was the main aspect which contributed for their preference.
\end{abstract}

Keywords: Project work. Mathematics teacher education. Teacher work. Mathematics education.

\footnotetext{
${ }^{1}$ Mestre em Educação Matemática. Coordenadora EAD, Licenciatura em Matemática, Instituto de Ensino Rio Claro. Rio Claro, SP. dirlenecattai@gmail.com

${ }^{2}$ Doutora em Educação. Docente do Departamento de Matemática e do Programa de Pós-Graduação em Educação Matemática, Instituto de Geociências - IGCE, Universidade Estadual Paulista (Unesp). Rio Claro, SP. mirgps@rc.unesp.br

${ }^{1}$ Av. $18, n^{\circ} 1161$, apto. 94

Santa Cruz - Rio Claro, SP

$13.500-490$ 


\section{Introdução}

O objetivo deste texto é apresentar resultados de uma pesquisa que procurou discutir as características da formação inicial e continuada dos professores de Matemática que atuam no Ensino Fundamental e Médio e que utilizam trabalhos com projetos na sua prática docente. A pesquisa analisa também a forma de implementação dessa proposta pelos professores.

O que nos motivou para a realização da pesquisa foi o fato de que, embora o trabalho com projetos esteja sendo altamente recomendado pelas agências que normalizam a atividade educacional e várias escolas já estejam utilizando essa metodologia, ainda é pouco conhecida a implicação que isso traz para o trabalho docente e as demandas para os formadores. Consideramos que os resultados obtidos trazem contribuições nesse sentido.

A seguir, apresentamos uma perspectiva teórica para o trabalho com projetos nas escolas, para, então, apresentarmos uma discussão dos dados coletados.

Os dados são provenientes de entrevistas realizadas com dez professores de Matemática que atuam no Ensino Fundamental ou Médio e que, na época, possuíam alguma experiência com o trabalho com projetos em suas aulas. Optamos por dar nomes fictícios aos participantes da pesquisa. Dessa forma, os denominamos: Rose, José Antônio, Solange, Marta, Mateus, Carla, Joyce, Márcia, Célia e Pedro. Os dois primeiros são da Bahia; Solange e Marta, de Minas Gerais; Mateus, do Rio Grande do Sul, e os demais, de São Paulo. Além das entrevistas, contamos ainda com duas fichas preenchidas pelos professores: uma delas com dados referentes à formação e atuação profissional de cada um e a outra com as características das escolas nas quais eles trabalham.

\section{Trabalho com Projetos em Educação}

Nos últimos anos, muito se tem falado sobre projetos na área de educação. Porém, esse não é um tema novo. De acordo com Knoll (1997), a história dos projetos no campo educacional tem seus primórdios em 1590 nas escolas de arquitetura. Na educação básica, a idéia de trabalho com projetos surge na década de 1920, no século passado. Suas raízes estão na teoria do filósofo, psicólogo e pedagogo norte-americano John Dewey, que tem como proposta uma escola centrada no aluno. Para Dewey (1959, p. 258) “a passividade é o oposto do pensamento; que não é só um sinal de ausência do juízo e da compreensão pessoal, mas também invalida a curiosidade, provoca a distração mental e faz da aprendizagem uma tarefa, não um prazer". De acordo com suas idéias, o aluno é responsável pela sua aprendizagem, enquanto "o professor é um guia, um diretor, pilota a embarcação, mas a energia propulsora deve partir dos que aprendem" (DEWEY, 1959, p. 43).

Foi Kilpatrick, colega de Dewey na Faculdade de Educação da Universidade de Columbia, no artigo "The Project Method”, publicado em 1918, quem primeiro utilizou a palavra "projeto" para designar uma metodologia de ensino na escola, de modo que contemplasse as idéias de Dewey.

Nos dias atuais, os trabalhos com projetos ressurgem com o mesmo significado e, segundo Nogueira (2005), situam-se entre um modismo descabido e uma excelente proposta 
para a formação integral do aluno. No entanto, para que seja aproveitado o lado bom dessa proposta, é preciso pensar na maneira como está sendo feita sua integração na prática docente.

O trabalho com projeto nas escolas, não deve ser visto apenas como "[...] um plano de trabalho ou um conjunto de atividades bem organizadas. Há muito mais na essência de um bom projeto" (ALMEIDA, FONSECA JR., 2000, p. 23). Essa proposta de trabalho demanda novos papéis para alunos, professores e comunidade escolar em geral.

Os projetos são organizados em torno de um tema ou um problema a ser investigado. A abordagem desse tema pode ocorrer em parceria com outras disciplinas. Há a recomendação para que sejam escolhidos temas da atualidade e do interesse dos alunos, levando-se em consideração a possibilidade de trabalhar os problemas existentes na comunidade, bem como "sua relevância para o desenvolvimento de conteúdos programáticos" (MONTEIRO, POMPEU JR., 2001, p. 81).

Nessa perspectiva, os projetos possibilitam trabalhar os temas transversais, propostos pelos Parâmetros Curriculares Nacionais (BRASIL, 1998), abordando problemas do cotidiano dos alunos, além de desenvolver os conteúdos curriculares de uma maneira mais investigativa.

Fazer uso de projetos em sala de aula é uma forma de organizar o trabalho pedagógico diferente daquela tradicional, em que o professor explica e o aluno faz exercícios. "Uma idéia básica do trabalho com projetos é permitir que os alunos se tornem ativos de uma forma muito diferente da de fazer exercícios" (SKOVSMOSE, 2002, p. 52). Eles devem permitir que o aluno perceba sua autoria e aprenda fazendo. Isso não significa que a presença do professor não seja importante. Seu papel é fundamental: é ele "que ouve, questiona e orienta, visando propiciar a construção do conhecimento do aluno" (PRADO, 2003, p. 3).

Para que os alunos se tornem ativos nas atividades escolares, é preciso que os temas dos projetos façam parte de seus interesses. Ninguém aprende aquilo que não tem intenção de aprender. A aprendizagem depende da motivação, do envolvimento, do esforço e da capacidade de cada um. O processo de aprendizagem é pessoal, ninguém pode aprender por outra pessoa, da mesma forma que ninguém pode ensinar para aquele que não tem interesse em aprender (ANDRADE, 2003).

Desde sua origem, na proposta de Kilpatrick (1918) e Dewey (1959), o interesse representa um ponto primordial no trabalho com projetos. Não é possível projetar aquilo que não faz parte das intenções de quem projeta. A esse respeito, Machado (2004, p. 7) diz que "não se pode ter projetos pelos outros". Por isso, a literatura critica fortemente os projetos planejados por terceiros, ou seja, sem a participação daqueles que deverão executá-los.

De acordo com Nogueira (2004), a grande maioria dos projetos praticados nas escolas trata-se, na verdade, de pseudoprojetos, já que, em geral, eles são resultados de um trabalho solitário da coordenação pedagógica das escolas, que decide sobre: o tema a ser trabalhado, os objetivos, o público-alvo, as ações e estratégias de trabalho a serem utilizadas em seu desenvolvimento. Segundo esse autor, os projetos assim idealizados provêm da falta de conhecimento do real significado do ato de projetar.

Para Almeida e Fonseca Jr. (2000, p. 22), "trabalhar com projetos é uma forma de facilitar a atividade, a ação, a participação do aluno no seu processo de produzir fatos sociais, de trocar informações, enfim, de construir conhecimento". Concordamos com esses autores quando dizem que os projetos são oportunidades excepcionais na prática de sala de aula por possibilitar um arranjo diferente nas dinâmicas de aprendizagem. 
Esse arranjo diferente proporcionado pelo trabalho com projetos privilegia a negociação entre professores e alunos na tomada de decisões e altera, de maneira substancial, a dinâmica da sala de aula. Além disso, os projetos possibilitam ao aluno refletir e buscar soluções para questões de seu cotidiano. Nessa abordagem, o aluno é levado a investigar, a testar conjecturas, a tomar decisões e a tirar conclusões. Ele não é, simplesmente, aquele que recebe informação. $\mathrm{O}$ aluno busca e processa esta informação na construção do seu conhecimento.

No papel do professor, também ocorrem mudanças. Ele não é mais o "detentor do conhecimento", as informações não partem apenas dele. Seu papel não é simplesmente transmitir conhecimentos. Segundo Almeida (1999, p. 3), "o professor é o consultor, articulador, mediador, orientador, especialista e facilitador do processo em desenvolvimento pelo aluno".

Dessa forma, o professor tem extrema importância no desenvolvimento de projetos. É ele quem planeja os objetivos, os recursos humanos e materiais que deverá disponibilizar para seu desenvolvimento, o tempo necessário para sua execução, o público-alvo, as disciplinas que irão envolver, além de orientar as atividades dos alunos.

Ao desenvolver projetos em suas aulas, o professor pode fazer uso das mais diferentes mídias disponíveis em sua escola, entre elas podemos citar: jornais, revistas, Internet, calculadoras e softwares educacionais, o que normalmente não acontece nas aulas tradicionais.

O uso das tecnologias da comunicação e informação (TIC) abre um grande leque de possibilidades no processo de implementação de projetos nas escolas. Além de serem úteis como fontes de informações, servem de suportes para a comunicação e publicação dos trabalhos desenvolvidos pelos alunos.

No desenvolvimento de projetos, a escolha do tema se constitui uma das etapas fundamentais. Segundo Nogueira (2005), o papel do professor na definição do tema de um projeto é detectar a necessidade de estudá-lo e apresentá-lo aos alunos. É sua função ainda, de acordo com esse autor: analisar a relevância desse tema, a possibilidade de desenvolvê-lo interdisciplinarmente; verificar se seu estudo propiciará novos conhecimentos, possibilitando provocar mudanças de atitudes nos alunos, e atender às necessidades e anseios de seus participantes. No entanto, para trabalhar com projetos, o professor precisa conhecer os problemas e interesses de seus alunos, para que possam negociar os temas a serem estudados.

Almeida e Fonseca Jr. (2000) defendem que um bom projeto depende de uma boa questão de investigação. Essa questão deve ser construída coletivamente, por professores e alunos e tratar de problemas não apenas internos à escola. Além desses, devem referir-se, ainda, a problemas da comunidade em geral.

Outro aspecto defendido por esses autores está relacionado à interdisciplinaridade, pois eles acreditam que, para dar conta de resolver os problemas levantados pelos alunos e pela sociedade, o planejamento e o desenvolvimento do projeto devem ser feitos pelo conjunto dos professores que atuam na escola ou em determinada turma. Além de contar com os parceiros de outras disciplinas, há que se contar também com a participação de outras pessoas, até mesmo externas à escola. Estas parcerias começam com os que estão mais próximos, os alunos de outras escolas, os pais, a comunidade e, depois, partem para os mais distantes.

O planejamento é outro elemento importante a ser considerado no desenvolvimento de projetos. Ele deve ser feito de forma coletiva, entre professores e alunos. O professor planeja a forma de torná-lo viável, enquanto os alunos planejam suas ações: o que pesquisar, 
como e onde pesquisar, qual será o produto final, qual será a responsabilidade de cada integrante do grupo no desenvolvimento das ações.

Parece ser unânime, na literatura, que o desenvolvimento de projetos exige um planejamento bem elaborado, porém não se pode torná-lo o único caminho possível a ser seguido, pois cada projeto tem suas características particulares. Dessa forma, havendo necessidade, deve-se mudar de rotas e replanejar as ações.

Segundo Prado (2003, p. 2), "aqueles que buscam apenas conhecer os procedimentos, os métodos para desenvolver projetos, acabam se frustrando, pois não existe um modelo ideal pronto e acabado que dá conta da complexidade que envolve a realidade de sala de aula, no contexto escolar".

No desenvolvimento de projetos, além da escolha do tema e do planejamento, devese ter um bom sistema de registro e organização dos dados. Isso irá contribuir para se ter uma visão dos caminhos percorridos na execução das atividades do projeto e o acompanhamento do aprendizado construído (ALMEIDA, FONSECA JR., 2000).

Professores e alunos deverão ter seus sistemas de registros. No registro dos professores deverá constar: o tema, uma apresentação do projeto, a justificativa, os objetivos a serem atingidos, quais pessoas serão envolvidas, o plano de ação, as formas de avaliação, entre outros. Além disso, professores e alunos devem registrar os caminhos percorridos no desenvolvimento das atividades do projeto. O registro dos alunos poderá revelar ao professor suas opiniões, dificuldades e interesses. Isso possibilitará fazer os ajustes necessários e possíveis mudanças de rotas, além de contribuir para definir novos projetos. Já o registro dos professores poderá revelar se os objetivos previstos foram atingidos ou não, apontando, assim, melhorias para os trabalhos futuros.

É importante observar que, para se caracterizar como projeto, além do plano, é preciso que haja ação. Assim, quando os professores fazem um esboço de um projeto, escrevendo os objetivos que pretendem atingir, quais os caminhos e recursos que serão utilizados, qual o público-alvo, quais são os possíveis parceiros, entre outros pontos, eles apenas iniciaram o projeto. Sua concretização se dá por meio das ações, da análise dos caminhos percorridos, do replanejamento e da mobilização dos recursos para seu desenvolvimento (CORTESÃO, LEITE, PACHECO, 2002).

No desenvolvimento de projetos, faz-se necessário um produto resultante do trabalho. Este produto deverá tornar-se público, por meio de apresentações e divulgações que podem ocorrer por intermédio de seminários, publicações em jornais ou qualquer outra forma. Esta é uma forma de incentivo aos alunos, pois assim suas atividades escolares são valorizadas. E, segundo Almeida e Fonseca Jr. (2000), os alunos passam a desenvolvê-las com mais seriedade. Concordamos com esses autores quando dizem que o envolvimento dos alunos na preparação do produto e divulgação dos resultados constitui-se em momentos riquíssimos de aprendizagem e de compromisso com o bem comum, além de despertar seus interesses para estudos posteriores.

A divulgação dos produtos obtidos nos projetos pode contribuir, ainda, para resolver problemas existentes na comunidade, "tais como os que envolvem a questão do lixo, o desperdício, a necessidade de reciclagem e reaproveitamento de materiais, a qualidade ambiental da comunidade" (BRASIL, 1998, p. 41), entre outros. 
Segundo Nogueira (2005), as primeiras apresentações feitas pelos alunos, normalmente, são pouco espontâneas, mas com o tempo elas tendem a melhorar. Em sua opinião, a importância na divulgação dos resultados reside no fato de que os alunos ficariam desmotivados se seus trabalhos fossem engavetados. Além disso, as apresentações feitas pelos alunos contribuem para que eles exponham suas descobertas, hipóteses e conclusões, e permitem ao professor avaliar as diversas fases de um trabalho com projetos.

Há um consenso na literatura de que a avaliação do projeto deve ser feita de maneira global, passando por todas as suas fases. Segundo Nogueira (2005), avaliar o projeto implica ir além da avaliação da aprendizagem dos alunos, significa verificar se os objetivos previstos foram atingidos. No processo de avaliação de um projeto, deve-se considerar ainda, de acordo com esse autor, a participação e contribuição de cada um dos envolvidos, destacando os pontos negativos que, por ventura, vierem a acontecer por falta de comprometimento de alguns membros do grupo. Com relação aos alunos, eles devem ser incentivados a destacar os pontos positivos e negativos do seu projeto, fazer suas críticas e dizer o que poderia ser feito para torná-lo melhor.

Pelo exposto, um dos principais papéis do professor ao trabalhar com projetos é acompanhar e auxiliar os alunos em toda sua trajetória. Mesmo que nesse acompanhamento ele tenha feito interferências no sentido de abordar ou aprofundar conteúdos, ao final do projeto, ele deve tentar relacionar os resultados obtidos com os conteúdos que, por ventura, não foram abordados. Além disso, espera-se que o professor faça o fechamento do projeto, momento em que destacará o problema e as dúvidas iniciais, os interesses, as propostas de ações, os resultados e as conclusões a que chegaram (NOGUEIRA, 2005).

Almeida (2003) consegue sintetizar de forma bastante precisa o processo de desenvolvimento de projetos no âmbito educacional:

O projeto é desenvolvido pelas pessoas que pensam e atuam em sua realização. Os autores são aqueles que participam em todo o desenvolvimento do projeto, concebem e discutem as problemáticas, descrevem e registram um plano para investigá-las e produzir resultados, desenvolvem as ações e avaliam continuamente se os resultados que vão sendo obtidos são aceitáveis em termos de satisfazer as intenções desejadas, responder às perguntas iniciais ou avançar em sua compreensão e até alterar as perguntas iniciais ou levantar novas perguntas. (ALMEIDA, 2003, p. 2)

\section{Professores que trabalham com projetos}

Conforme já mencionamos, os professores são elementos fundamentais para o sucesso de trabalho com projetos na escola. A seguir, trataremos especificamente desse tema com base nas entrevistas feitas com os professores da Educação Básica. 
A formação do professor de matemática e ...

\section{Formação dos professores que trabalham com projetos}

Os professores entrevistados possuem uma faixa etária bastante variada, o que não nos permite afirmar que somente aqueles mais experientes ou os mais novatos são os que trabalham com projetos. A experiência desses professores varia de um a trinta anos de trabalho. Carla, por exemplo, iniciou sua carreira profissional há apenas um ano, enquanto professores como Marta e Pedro têm, respectivamente, 25 e trinta anos de trabalho docente. O tempo de serviço dos professores entrevistados pode ser visto na Tabela 1.

\begin{tabular}{cl}
\hline Tabela 1. Tempo de trabalho docente. & \\
\hline Tempo de trabalho docente (anos) & \multicolumn{1}{c}{ Professores } \\
\hline Menos de 5 & Carla \\
De 6 a 10 & Joyce e Mateus \\
De 11 a 15 & José Antônio, Márcia e Rose \\
De 16 a 20 & Célia \\
Acima de 20 & Marta, Pedro e Solange \\
\hline
\end{tabular}

Quanto à formação inicial desses professores, não há indícios de que ela os tenha influenciado a utilizar projetos em sua prática pedagógica. O preparo para desenvolver trabalhos dessa natureza foi sendo construído ao longo de suas carreiras. Alguns participaram de cursos, que serviram de suporte para a implementação da proposta em sala de aula, enquanto outros apenas foram orientados pela coordenação e direção da escola. Nenhum deles mencionou o curso de licenciatura como sendo responsável por essa formação. Ademais, apenas Carla e Mateus tiveram contato com essa prática nesse nível de ensino. Porém, Carla disse que está aprendendo a trabalhar realmente com projetos por meio de sua atuação como professora. Matheus fez questão de enfatizar que sua professora de Prática de Ensino não lhe disse que a atividade na qual ele se inspirou para desenvolver seu primeiro projeto - de retirar uma reportagem interessante de uma revista para ser trabalhada em sala de aula - se tratava de um projeto. Além disso, quando estava cursando a licenciatura, Mateus já trabalhava como professor. Hoje, após leituras que fez no mestrado e doutorado, ele diz ter uma visão diferente a respeito de projetos.

São vários os autores que tratam da formação proporcionada pela prática. Lima e Reali (2002, p. 224) dizem que:

Parece haver consenso, entre os estudiosos da educação, quanto ao fato de que os professores aprendem através da prática profissional, no contexto da escola e da sala de aula, na interação com alunos, colegas, especialistas etc. enfrentando e resolvendo problemas, pensando sobre o que fazem e como fazem. 
De acordo com Larrosa (2002), experiência é aquilo que se passa com as pessoas, é aquilo que acontece em suas vidas e que as forma e as transforma. Desta maneira, "é incapaz de experiência aquele a quem nada lhe passa, a quem nada lhe acontece, a quem nada the sucede, a quem nada o toca, nada lhe chega, nada o afeta, a quem nada o ameaça, a quem nada ocorre" (LARROSA, 2002, p. 25).

Esse autor define o saber da experiência como aquele adquirido pelo modo como as pessoas respondem ao que lhes acontece e ao modo como dão sentido aos acontecimentos. Isto significa que duas pessoas que viveram um mesmo acontecimento podem não compartilhar a mesma experiência, já que esta depende dos sentidos que foram atribuídos a esse acontecimento. Desta forma, a experiência é singular. Na opinião deste autor, uma pessoa não pode aprender com a experiência de outra, a menos que ela seja de alguma maneira revivida e tornada própria.

Esta definição dada por Larrosa (2002) nos ajuda a compreender o fato de professores pertencentes a um mesmo sistema de ensino, ou a uma mesma escola, agirem de maneiras diferentes, quando são confrontados com as propostas de mudanças. Há aqueles que estão sempre abertos a refletir sobre sua prática e experimentar novos métodos de trabalho, enquanto existem outros que não aceitam nenhum tipo de transformação.

Para Lima e Reali (2002), os saberes proporcionados pela experiência são gerados na atuação profissional do professor. São esses saberes que "fundamentam suas ações cotidianas e despontam como vitais no trabalho docente, pois tendem a se converter em habitus" (LIMA, REALI, 2002, p. 224).

No caso dos professores entrevistados, há indícios de que o conhecimento proporcionado pela experiência muito contribuiu para o desenvolvimento de projetos em suas aulas. Conforme mencionamos anteriormente, embora seja bastante nova, a professora Carla, em apenas um ano de exercício do magistério, já aprendeu bastante com sua prática. Solange recorda o fato de que, no início de sua carreira profissional era seguidora de livro didático, sem ver possibilidades para outras práticas. Hoje, por meio da sua experiência e da sua formação continuada, isso não mais acontece. Ela usa o livro didático como um dos recursos, e não mais como o único, da forma que fazia inicialmente. José Antônio também faz referência à sua experiência de sala de aula, como sendo um dos fatores que o possibilitou trabalhar com projetos. Isso fica evidente quando ele diz que não encontrou muita dificuldade no desenvolvimento de projetos, "pois já vinha fazendo trabalhos parecidos em sala de aula com outros professores, ainda que esta metodologia, não fosse adotada pelo Sistema de Educação da Bahia". Márcia foi enfática ao dizer: "Ab! Depois que você dá aulas pra alunos do $2^{\circ}$ e do $3^{\circ}$ 'colegial', aquele monte de ferinhas te fazendo milhöes de perguntas [...] Depois que eu passei um ano e meio de provação [...] Que eu ralei naquele um ano e meio, então eu não tenho medo de mais nada. Medo assim, de pegar e falar: Vou fazer? Ih, faço tudo?'.

Além da experiência com a prática, a participação em cursos de formação continuada - cursos feitos após a graduação - foi outro aspecto que exerceu forte influência sobre os professores de Matemática que trabalham com projetos, tornando-se uma característica marcante no perfil deles. Todos, sem nenhuma exceção, deram continuidade a seus estudos após o curso de licenciatura, por meio de cursos de especialização, extensão, mestrado, doutorado e da participação em congressos e eventos. Esta situação pode ser vista na Tabela 2. 
A formação do professor de matemática e ...

Tabela 2. Formação continuada dos professores entrevistados.

\begin{tabular}{|c|c|}
\hline Cursos feitos & Professores \\
\hline Especialização & Célia, Joyce, José Antônio, Marta, Rose e Solange \\
\hline Outra Graduação & Célia e Pedro \\
\hline Mestrado - Concluído & Carla, Marta, Mateus e Pedro \\
\hline Mestrado - em andamento & Joyce, Márcia e Solange \\
\hline Doutorado - em andamento & Mateus \\
\hline
\end{tabular}

O perfil do professor de Matemática que trabalha com projetos é marcado por sua dinamicidade. Este professor está bastante preocupado com seu desenvolvimento profissional, por isso a participação maciça em cursos de formação continuada. Dessa forma ele se mantém em sintonia com as tendências da Educação. Não se acomoda e chega a se mostrar uma pessoa inquieta, que percebe a necessidade de mudança e que busca aperfeiçoar-se naquilo que faz. Enfim, o professor de Matemática que trabalha com projetos está preocupado em oferecer uma educação de qualidade a seus alunos.

Mesmo aqueles que desenvolvem projetos por exigência da escola, ou seja, cuja decisão por trabalhar com projetos não é sua, buscam essa qualidade. Caso contrário, eles não se envolveriam com tanta dedicação nos projetos sugeridos pela escola. Percebemos que, mesmo aqueles que são praticamente obrigados a trabalhar com projetos, como é o caso de Rose, tentam fazer o trabalho da melhor maneira possível.

Outra característica presente no perfil dos professores que trabalham com projetos é o seu lado pessoal, suas crenças, seus valores, suas concepções de ensino, interferindo em sua prática de sala de aula. É o que Nóvoa (1995) diz ao referir-se à impossibilidade de separar o lado pessoal do professor de sua atuação profissional. Em suas palavras:

A resposta à questão, Porque é que fazemos o que fazemos na sala de aula?, obriga a evocar essa mistura de vontades, de gostos, de experiências, de acasos até, que foram consolidando gestos, rotinas, comportamentos com os quais nos identificamos como professores. Cada um tem o seu modo próprio de organizar as aulas, de se movimentar na sala, de se dirigir aos alunos, de utilizar os meios pedagógicos, um modo que constitui uma espécie de segunda pele profissional. [...] É impossível separar o eu profissional do eu pessoal. (NÓVOA, 1995, p. 16-7) 
Cattai, M. D. S.; Penteado, M. G.

\section{Maneiras como os professores trabalham com projetos}

A Tabela 3 apresenta uma síntese das formas como os professores trabalham com projetos.

Tabela 3. Maneiras de trabalho com projetos nas escolas.

\begin{tabular}{lll}
\hline \multicolumn{1}{c}{ Modalidade de trabalho com projetos } & \multicolumn{1}{c}{ Professores } \\
\hline Individualmente e por sua própria iniciativa & $\begin{array}{l}\text { Carla e Joyce } \\
\text { Marta e Mateus }\end{array}$ & $\begin{array}{c}\text { Vários temas por turma } \\
\text { Tema único por turma }\end{array}$ \\
$\begin{array}{l}\text { Sugeridos pela escola - todas as disciplinas } \\
\text { trabalham o mesmo tema, sem integração }\end{array}$ & Célia, Márcia, Rose e Pedro \\
Coletivamente & José Antônio e Solange \\
\hline
\end{tabular}

Por meio dos relatos dos professores participantes da pesquisa, identificamos três formas diferentes de trabalhar com projetos. Há os que desenvolvem projetos individualmente e a partir de iniciativa própria. Aqui estão incluídos: Carla, Joyce, Marta e Mateus. Esses professores não envolvem colegas de outras disciplinas para dar suporte à investigação do tema. Cabe ressaltar, que embora eles trabalhem de forma individual e pela própria iniciativa, a maneira como isso se dá ainda difere uma da outra. Esse item poderia ser dividido em dois subitens: um formado por professores que propõem o estudo de um único tema com toda sua turma, que é o caso da Marta e do Mateus, e outro, formado por professores que trabalham com vários temas em uma mesma turma, como Carla e Joyce.

Carla, normalmente, trabalha com vários temas por turma, sendo que cada grupo de alunos os escolhe livremente, de acordo com seus interesses. Joyce, por sua vez, prefere apresentar uma lista com sugestões de temas matemáticos e um pequeno texto a respeito de cada um deles. Os grupos de alunos leem os textos e escolhem aquele que consideram ser o mais interessante. Já Marta e Mateus sugerem um tema que julgam ser de interesse dos alunos e trabalham somente com ele.

Outra maneira identificada é aquela em que o professor trabalha com projetos por sugestão da escola, que, por meio da coordenação pedagógica, decide quais temas todas as disciplinas devem desenvolver. Aqui estão incluídos: Márcia, Célia, Pedro e Rose. Embora seja um único tema para toda a escola, isso não implica que os professores trabalhem em conjunto em um mesmo projeto. Em geral, trabalham dentro de sua própria disciplina. É como se os alunos desenvolvessem diversos projetos sobre um mesmo tema, e não um único projeto com a orientação de diversos especialistas (os professores das diferentes disciplinas). Isso pode tornar-se cansativo para eles. Os alunos de Márcia, por exemplo, quando todos os professores trabalhavam com o tema do consumo de energia, disseram: “Ih, mas de novo esse tema?'. Eles já estavam cansados do tema energia, pois todos os outros professores estavam propondo atividades sobre o mesmo assunto, sem fazer relação com o que vinha ocorrendo nas demais 
disciplinas. Neste caso, tem-se uma caricatura de projetos, um pseudoprojeto (NOGUEIRA, 2004; THURLER, 2001).

Finalmente, há aqueles professores que trabalham coletivamente, é o caso de Solange, em parceria com seus colegas, e de José Antônio com os seus. A escolha do tema é feita a partir de negociação entre os professores e seus alunos. As atividades propostas nos projetos são planejadas semanalmente pelo grupo de professores, os quais atuam nas turmas em que estes estão sendo desenvolvidos. O grupo de professores ao qual Solange pertence não faz divisão de atividades por disciplinas. Cada professor fica responsável por orientar um grupo de alunos, independente do conteúdo que será trabalhado. Apenas as discussões de questões mais específicas de cada disciplina ficam a cargo do professor correspondente. Já no grupo de José Antônio, as atividades são desenvolvidas durante o horário das aulas das disciplinas, conforme o conteúdo a que se refere.

Com relação aos temas dos projetos, alguns dos professores entrevistados propõem aqueles que consideram ser do interesse dos alunos. Enquanto outros dão maior liberdade para os alunos participarem da escolha. Em alguns casos, o tema surge a partir da percepção, por algum professor, da necessidade (e relevância) de estudá-lo. Há, ainda, professores que sugerem os temas pensando nos conteúdos que poderão trabalhar. Entretanto, há um número considerável de professores que trabalham com projetos cujos temas são propostos pela coordenação da escola. O que não é considerado ideal, pois, conforme a literatura, os temas dos projetos devem partir das pessoas que irão desenvolvê-los, ou seja, os professores e alunos. Porém, mesmo não sendo a forma ideal, ainda vemos vantagens neste tipo de trabalho quando comparado com a aula tradicional, no que se refere ao planejamento, já que essas aulas são planejadas com mais dedicação. E, sobretudo, as vantagens estão relacionadas a uma maior participação dos alunos. Os professores fizeram bastante referência ao maior interesse do aluno quando trabalham com projetos.

O planejamento das ações foi uma preocupação que esteve sempre presente nos trabalhos dos professores participantes da pesquisa.

Em nossa opinião, o planejamento é uma das fases mais difíceis de serem implementadas conforme propõe a literatura - em parceria com os alunos, dando-lhes autonomia, pois já está impregnado, na pessoa do professor, de que este é um trabalho seu. Mesmo assim, percebemos que, em alguns casos, os alunos conseguiram desempenhar a contento seus papéis no planejamento de suas ações, sob a orientação dos professores.

$\mathrm{Na}$ maioria dos projetos relatados pelos entrevistados, professores e alunos exerceram bem seus papéis. O professor auxiliando os alunos na busca da informação, na preparação e apresentação do produto final. Enquanto os alunos - embora em alguns casos a participação deles na escolha do tema e no planejamento não tenha sido a ideal - participaram ativamente no desenvolvimento das atividades planejadas.

Com relação ao registro, este representa uma dificuldade tanto dos alunos como dos professores. Infelizmente, registrar os caminhos percorridos na realização de uma atividade não é uma prática comum nas escolas, talvez pela falta de tempo. Uma das formas que acreditamos poder minimizar a dificuldade dos alunos é seguir as sugestões dadas por Nogueira (2005). Sua proposta é que o professor elabore, pelo menos nos trabalhos iniciais, um encaminhamento com algumas frases a serem completadas pelos alunos ao longo do desenvolvimento do projeto. Esta é uma forma de fazer com que os alunos criem o hábito de escrever. 
Salvo algumas exceções, as avaliações dos projetos desenvolvidos pelos professores entrevistados aconteceram no sentido de destacar os pontos positivos e negativos dos mesmos, buscando o aperfeiçoamento de trabalhos futuros. Um exemplo disso pode ser visto na fala de Rose: "No final, todas as turmas fizeram uma apresentação de seus trabalhos. A apresentação foi aberta à comunidade em geral. Foi feita uma avaliação pelos alunos, em que eles listaram as ações desenvolvidas pelo grupo, o que acharam positivo e o que poderia ter sido feito melhor".

Nos relatos dos professores não ficou evidenciado o cumprimento dos ajustes finais ou o encerramento do projeto, conforme propõe a literatura. Normalmente, o projeto é encerrado com a apresentação do produto final. No entanto, cabe ressaltar que consideramos importante que o professor faça um apanhado geral do projeto, tentando relacionar conteúdos e questões que poderiam ter sido tratados em seu desenvolvimento e que não o foram.

\section{Considerações finais}

Desde suas origens, os trabalhos com projetos apresentam um caráter democrático. Dewey (1959) propunha e defendia, por suas idéias inovadoras, as transformações sociais. Sua expectativa era de uma educação capaz de formar o cidadão para a autonomia, em oposição à submissão.

Os professores participantes desta pesquisa também buscam esta educação para o exercício da democracia. O trabalho deles está voltado para a formação do educando para além dos conteúdos curriculares, levando-o a compreender e atuar no mundo a sua volta. Por isso, estão preocupados em contextualizar a Matemática, possibilitando a percepção de sua aplicabilidade, além de relacioná-la com as demais áreas do conhecimento.

No que se refere à formação destes professores, a participação em cursos de formação continuada tornou-se uma das características mais marcantes em seus perfis. Além disso, sua formação recebeu influência do conhecimento proporcionado pela prática e de interferências de seu lado pessoal. A decisão de trabalhar com projetos está intimamente relacionada aos valores, crenças e convicções que eles têm. Os professores de Matemática que trabalham com projetos são pessoas preocupadas com o seu desenvolvimento profissional, e preocupadas, ainda, em oferecer uma educação de qualidade para seus alunos. Eles têm uma concepção de educação que vai além da transmissão de informações.

Talvez a mais surpreendente das conclusões desta pesquisa seja a constatação de que os cursos de formação inicial de professores ainda não oferecem preparo para que eles trabalhem com projetos. Ficou evidente nos relatos dos professores - inclusive dos novatos e que, consequentemente, cursaram a licenciatura recentemente - que os cursos de formação inicial pouco têm contribuído para que o futuro professor tome conhecimento desta proposta de trabalho. Embora o termo projeto esteja bastante presente nas escolas, ainda há uma grande carência da discussão desta proposta na formação inicial de professores. Nenhum dos entrevistados mencionou este nível de ensino como sendo responsável pelo preparo por desenvolver trabalhos desta natureza.

Esta carência percebida na formação inicial foi superada pela continuada. Os participantes da pesquisa tiveram apoio e estímulos oriundos de cursos de formação continuada, tais como: mestrado, especialização ou cursos promovidos pelas Secretarias de Educação. Para 
nós, com um suporte desta natureza, é possível que um maior número de professores desenvolva uma educação matemática que privilegie atividades investigativas, que constituem o cerne da proposta de trabalho com projetos.

Acreditamos ser difícil, para um professor, desenvolver projetos em sua prática, sem ter recebido formação para isso. Daí, a necessidade de maior investimento em programas de formação inicial e continuada que tratem desta questão. Não se pode esperar que os professores mudem suas práticas, se não tiveram contato com esse tipo de trabalho em sua formação. Concordamos com Mizukami et al. (2003, p. 39), quando dizem que "não se pode exigir que docentes realizem em suas aulas o que não vêem aplicado na própria formação". Para essas autoras, é preciso haver coerência entre o que eles aprenderam e o que esperam que ensinem em suas aulas. Isso se refere tanto aos conteúdos quanto à metodologia.

Com relação à prática dos professores participantes desta pesquisa, observamos que nem sempre o que a literatura apresenta é levado em consideração, pois vários temas são sugeridos pela escola sem a participação dos alunos e, em alguns casos, até mesmo sem a participação dos professores. É comum acontecer de os projetos serem elaborados pela diretora ou coordenadora pedagógica das escolas, porém, a literatura condena essa prática, já que ninguém pode viver o que outra pessoa projetou. Sendo assim, como professores e alunos vão se engajar em um projeto que não fora planejado por eles? (MACHADO, 2004). Neste caso, professores e alunos passam a ser meros executores de planos elaborados por terceiros. Isso acarreta pouco engajamento, já que não se sentem “donos” dos projetos. Além disso, há escolas inteiras trabalhando um único tema, porém de forma fragmentada, em que cada professor tenta encaixar um conteúdo de sua disciplina ao tema estudado, enquanto a literatura propõe o trabalho interdisciplinar.

Segundo Almeida e Fonseca Jr. (2000), experiências mal conduzidas levam as pessoas a acreditarem que a educação está vivendo o momento "da perda da identidade: cada um fala um pouquinho do que não conhece, de maneira superficial, sem identidade epistemológica" (ALMEIDA, FONSECA JR., 2000, p. 41). O que esses autores propõem é a busca por uma visão de conjunto, em que haja a integração das disciplinas. Essa integração, segundo eles, se dá por meio da colaboração entre professores e alunos.

Além disso, a literatura aponta para a possibilidade de desenvolver trabalhos com projetos para trabalhar conteúdos curriculares, mas essa é uma prática rara nas escolas (NOGUEIRA, 2005; SKOVSMOSE, 2000; HERNÁNDEZ, VENTURA, 1998; BRASIL, 1998). Usualmente, o que ocorre é o trabalho com um tema geral, no qual se busca desenvolver o conteúdo matemático necessário para compreender a situação investigada. Nesse caso, o foco do projeto não é compreender um tópico específico de matemática, mas sim usar o conteúdo matemático para compreender um tema não matemático. Essa abordagem requer tempo e certo desvio no tratamento dos conteúdos da disciplina, pois nem sempre os tópicos de matemática previstos para uma determinada série encaixam-se na investigação de um tema mais geral. Isso gera uma ansiedade nos professores, porque se veem diante de um conflito. Se, por um lado, são estimulados a trabalhar com projetos, por outro, são cobrados para que os alunos se saiam bem em provas de conteúdo específico. O professor fica com a sensação de sobrecarga de trabalho e currículo não cumprido.

Como forma de minimizar essa sensação, a implementação dos trabalhos com projetos na escola pode ser feita de acordo com a proposta de Skovsmose (2000), o qual defende 
que o importante é o professor criar ambientes de aprendizagens com diferentes referências. É uma proposta em que a investigação ganha papel central e pode ser desenvolvida a partir da referência matemática, que é com a qual o professor sente-se mais confortável para trabalhar. Aos poucos, pode ir alterando a referência de forma a tratar temas relacionados ao cotidiano dos alunos. Com essa aproximação, o professor abre espaço para o trabalho com projetos em sala de aula.

Ressaltamos que somente a formação do professor e sua boa vontade em implementar mudanças na escola não são garantia de sucesso. Consideramos valiosas as inovações feitas por professores, como é o caso dos participantes desta pesquisa. Porém, elas representam algo muito "tímido" se comparado com os desafios impostos à escola. Segundo Thurler (2001), existem professores que tentam, há muito tempo, romper com a organização escolar tradicional, mas essas tentativas, na maioria das vezes, fracassam. Isso se dá, por configurarem-se em um espaço muito limitado e pela falta de flexibilidade da escola.

Para que a escola consiga desempenhar adequadamente sua função, faz-se necessário uma profunda modificação em suas estruturas. Parafraseando Candau (2000, p. 76), é preciso "romper com o 'congelamento' que sofreu através do tempo".

Para que as mudanças aconteçam de fato, é preciso que todos os atores envolvidos estejam conscientes de sua necessidade. Dessa forma, não se trata de mudar apenas o trabalho do professor, e sim mudar a escola como um todo. Ela precisa ser reinventada, conforme propõem Almeida (1998), Candau (2000) e uma infinidade de outros pesquisadores.

\section{Referências}

ALMEIDA, F. J. As aparências enganam. In: MEC/SEED. Salto para o futuro: TV e informática na educação. Brasília: MEC/SEED, 1998. p. 73-80.

.; FONSECA JR., F. M. PROINFO: projetos e ambientes inovadores. Brasília: MEC/SEED, 2000.

ALMEIDA, M. E. B. Prática e formação de professores na integração de mídias: pedagogia de projetos e integração de mídias. Salto para o futuro/TV escola, Brasília, Boletim 2003. Disponível em: <http://www.tvebrasil.com.br/salto/>. Acesso em: 26 jul. 2005.

Projeto: uma nova cultura de aprendizagem. São Paulo: PUC, 1999. [mimeogr.]

ANDRADE, P. F. Aprender por projetos, formar educadores. In: VALENTE, J. A. (Org.). Formação de educadores para o uso de informática na escola. Campinas: Unicamp/ NIED, 2003. Disponível em: <http://www.nied.unicamp.br/oea/pub/livro4/>. Acesso em: 25 jun. 2007.

BRASIL. Secretaria de Educação Fundamental. Parâmetros Curriculares Nacionais: terceiro e quarto ciclos: apresentação dos temas transversais. Brasília: MEC/SEF, 1998. 
A formação do professor de matemática e ...

CANDAU, V. M. Cotidiano escolar e cultura(s): encontros e desencontros. In:

(Org.). Reinventar a escola. Petrópolis: Vozes, 2000. p. 61-78.

CORTESÃO, L.; LEITE, C.; PACHECO, J. A. Trabalhar por projectos em educação: uma inovação interessante? Porto: Porto Editora, 2002.

DEWEY, J. Como pensamos - como se relaciona o pensamento reflexivo com o processo educativo: uma reexposição. Trad. Haydée de Camargo Campos. 3. ed. São Paulo: Companhia Editora Nacional, 1959.

HERNÁNDEZ, F.; VENTURA, M. A organização do currículo por projetos de trabalho. 5. ed. Porto Alegre: Artes Médicas, 1998.

KILPATRICK, W. H. The project method. Teachers College Record, v. 19, n. 4, p. 319-35, 1918. Disponível em: <http://escolanova.net/>. Acesso em: 15 set. 2006.

KNOLL, M. The project method: its vocational education origin and international development. Journal of Industrial Teacher Education, Normal, Il., v. 34, n. 3, p. 59-80, 1997.

LARROSA, J. B. Notas sobre a experiência e o saber de experiência. Trad. João Wanderley Geraldi. Revista Brasileira de Educação, Rio de Janeiro, n. 19, p. 20-8, 2002.

LIMA, M. S.; REALI, M. M. R. O papel da formação básica na aprendizagem profissional da docência (Aprende-se a ensinar no curso de formação básica?). In: MIZUKAMI, M. G. N.; REALI, A. M. M. R. (Orgs.). Formação de professores, práticas pedagógicas e escola. São Carlos: EdUFSCar, 2002. p. 217-36.

MACHADO, N. J. Educação: projetos e valores. 5. ed. São Paulo: Escrituras, 2004.

MIZUKAMI, M. G. N. et al. Escola e aprendizagem da docência: processos de investigação e formação. 1. reimp. São Carlos: EdUFSCar, 2003.

MONTEIRO, A.; POMPEU JR., G. A Matemática e os temas transversais. São Paulo: Editora Moderna, 2001.

NOGUEIRA, N. R. Pedagogia dos projetos: etapas, papéis e atores. São Paulo: Érica, 2005.

Pedagogia dos projetos: uma jornada interdisciplinar rumo ao desenvolvimento das múltiplas inteligências. 5. ed. São Paulo: Érica, 2004.

NÓVOA, A. Os professores e as histórias da sua vida. In: professores. 2. ed. Porto: Porto Editora, 1995. p. 11-30. . (Org). Vidas de

PRADO, M. E. B. B. Pedagogia de projetos. Salto para o futuro/TV escola, Brasília, Boletim 2003. Série Pedagogia de projetos e integração de mídias. Disponível em: <http:// www.tvebrasil.com.br/salto/>. Acesso em: 26 jul. 2005.

SKOVSMOSE, O. Trabalho de projecto em matemática. In: PROFMAT, 7., 2002, Lisboa. Actas... Lisboa: APM, 2002, p. 52-7. 
Cattai, M. D. S.; Penteado, M. G.

Cenários para investigação. Bolema - Boletim de Educação Matemática, Rio Claro, v. 13, n. 14, p. 66-91, 2000.

THURLER, M. G. Inovar no interior da escola. Trad. Jeni Wolff. Porto Alegre: Artmed Editora, 2001.

Artigo recebido em agosto de 2008 e aceito em fevereiro de 2009 